\title{
Pesquisa qualitativa em Educação e Linguagem: histórico e validação do paradigma indiciário
}

\author{
Livia Suassuna*
}

[...] a imaginação, embora seguindo outros caminbos que não os do conbecimento científico, pode coexistir com esse último, $e$ até coadjuvá-lo, chegando mesmo a representar para o cientista um momento necessário na formulasão de suas bipóteses. (CALVINO, 1990, p. 103)

\section{Resumo:}

Este estudo, de cunho teórico, é parte de nossa tese de Doutorado em Lingüística pela UNICAMP, especificamente do capítulo em que discutimos a pesquisa qualitativa em Educação e justificamos a opção pelo paradigma indiciário para estudar fenômenos no campo da avaliação institucional e da aprendizagem em linguagem. Está dividido em seis partes, nas quais apresentamos, sucessivamente: uma caracterização do paradigma científico clássico; um breve histórico da crise do paradigma clássico; uma discussão conceitual sobre pesquisa qualitativa; as inter-relações existentes entre os aspectos quantitativo e qualitativo da pesquisa educacional; um comentário sobre os dados e os procedimentos analíticos; uma abordagem específica sobre o paradigma indiciário, com indicação de sua pertinência e relevância para a pesquisa educacional como um todo e para o tratamento de fenômenos da linguagem no interior da escola.

Palavras-chave: Pesquisa educacional. Pesquisa qualitativa. Educação e linguagem - pesquisa.

\footnotetext{
* Doutora em Lingǘstica pela UNICAMP. Professora da Universidade Federal de Pernambuco - Centro de Educação - Departamento de Métodos e Técnicas de Ensino.
} 


\section{O paradigma científico clássico}

Uma das marcas mais evidentes da modernidade é o paradigma sobre o qual se assentaram as ciências e o conhecimento. $\mathrm{Da}$ instauração do período moderno até o início do século $\mathrm{XX}$, a ciência se caracterizou pelo primado da racionalidade técnica e instrumental, expressa através de grandes sínteses explicativas - as chamadas metateorias -, as quais se legitimaram como modelos científicos dominantes, considerados intelectualmente plausíveis e aceitáveis (MATALLO JR, 1989a; MINAYO, 2000).

Dentro desses metamodelos, as diferenças, as especificidades e os detalhes dos fenômenos em estudo não tinham importância: o que valia eram exatamente as regularidades e as uniformidades observadas, uma vez que um dos objetivos principais da ciência era traçar um conjunto de leis gerais para explicar o mundo. O desprezo pela singularidade foi criticado por Santos (2000a). Segundo o autor, o paradigma clássico, apoiado na distinção entre o relevante e o irrelevante, arroga-se o direito de negligenciar o que considera irrelevante e, portanto, de não reconhecer nada do que não quer ou não pode conhecer.

Em outra obra (SANTOS, 2001), o autor também mostra os limites da ciência tradicional, na medida em que seus métodos implicam uma redução da complexidade do universo. Santos considera que a ciência moderna sempre insistiu em considerar o conhecimento ordinário como irrelevante, falso e ilusório. Assim procedendo, a racionalidade científica tornou-se um modelo totalitário, marcado pela desconfiança para com nossas experiências imediatas; por isso, conforme Santos, o conhecimento moderno é desencantado e triste.

Certeau (1999) diz que a modernidade é recortada em "insularidades científicas dominantes" e que as ciências modernas exerceram um duplo domínio: sobre o corpus que circunscrevem e sobre as operações que aí efetuam. Isso porque a cientificidade exige a delimitação e a simplificação de seus objetos. Assim, nossos saberes parecem considerar e tolerar apenas os objetos inertes de um corpo social. ${ }^{1}$

Do ponto de vista dos procedimentos, a ciência moderna se prende às propriedades da lógica formal, tomada como modelo unitário aplicável a qualquer construção científica. Livre das vicissitudes históricas, a racionalidade científica teria seu poder explicativo ancorado no princípio da invariância, sendo as leis gerais abstraídas dos casos particulares. 
Vários estudiosos da ciência apontam limites também nesse procedimento típico do paradigma científico moderno. Ginzburg (1999) salienta que a linguagem matemática e os métodos experimentais viraram modelos da ciência clássica, por atender às exigências de rigor e controle dos resultados, com base nas idéias de quantificação e repetibilidade dos fenômenos estudados. Foi exatamente por esses fatores que, para Ginzburg, a história nunca conseguiu se tornar uma ciência galileana.

Certeau (1999) considera que os métodos científicos clássicos conseguem definir o seu objeto, racionalizar a sua coleta, classificar os seus tipos e transformar os dados em algo que se possa reproduzir. A ciência moderna desenvolveu, para isso, uma linguagem operatória, cuja gramática e sintaxe formam sistemas construídos e controláveis (e, portanto, "escrevíveis", numa visão de ciência como forma específica de escritura).

Referindo-se especificamente às Ciências Sociais, Demo (1995) argumenta que os modelos científicos estruturais reduzem a "aparente balbúrdia do mito" e fazem valer o primado do método sobre a realidade.

Santos (2001) também critica o procedimento da racionalidade científica, mostrando, primeiramente, que ele pressupõe a previsão do comportamento futuro dos fenômenos e, em segundo lugar, que o conhecimento assim gerado, baseado na formulação de leis gerais, tem como pressuposto metateórico a idéia da ordem e da estabilidade do mundo, a idéia de que o passado se repete no futuro.

Em diversos trabalhos, Morin (1996a, 1996b, 1996c) reflete sobre a ciência moderna, apontando alguns de seus atributos, entre eles:

- a sustentação nos três pilares da certeza - ordem, separabilidade e lógica;

- a identificação da contradição com o erro científico;

- a disjunção operada entre sujeito e objeto, sendo a subjetividade tomada como contingência e fonte de erros.

Morin acha que a ciência moderna define aquilo que do mundo devemos ver, e que ela deixou de propor interrogações sobre si mesma, sua marcha, seus fundamentos e seu alcance. 


\section{A crise do paradigma clássico}

Ainda no século XIX, despontaram os primeiros sinais de insatisfação com o paradigma científico clássico. $\mathrm{O}$ acelerado ritmo do progresso trouxe instabilidade à própria ciência, e, paulatinamente, foi-se abandonando a idéia de que a verdade científica seria una e única, isso ocorrendo mesmo no âmbito das chamadas Ciências Exatas e Naturais (COSTA, 1996). Rapidamente, teorias clássicas eram refutadas e substituídas por outras, de tal sorte que elas passaram a ser vistas menos como conjuntos de verdades absolutas e mais como instrumentos e conceitos provisórios de entendimento da realidade (MATALLO JR., 1989b).

Esse movimento de relativização das verdades científicas se fez particularmente visível nas Ciências Sociais, cujos estudiosos começaram a se preocupar com a descrição da vida humana e social em seus aspectos cotidianos. Foi-se tornando consensual, a partir daí, a idéia de que as Ciências Sociais não tinham a mesma natureza das Ciências Naturais, exatamente por conta do seu objeto de estudo, que seria histórico, mutável, dinâmico.

A mutabilidade do objeto das Ciências Sociais seria decorrente da nãounivocidade da linguagem e das diferenças no desempenho de papéis por parte dos diversos atores sociais. As Ciências Sociais, então, seriam marcadas por um considerável pluralismo teórico e se concretizariam, mais do que como metateorias, como um conjunto de postulados básicos que orientam a pesquisa, aliados a procedimentos de seleção dos fatos e reconstrução de fenômenos. Não haveria, portanto, nas Ciências Sociais, um método único e rígido para selecionar fatos relevantes para a explicação científica (MATALLO JR., 1989a; VEIGA-NETO, 1996). Aliás, a própria distinção entre Ciências Sociais, de um lado, e Ciências Naturais, de outro, passou a não ter mais sentido, na medida em que mesmo essas últimas sofreriam de uma incontornável imprecisão, já que o observador poderia, a qualquer momento, interferir nos fenômenos e modificar seus comportamentos. Em virtude disso, já não se poderia mais estabelecer os modelos das Ciências Naturais como paradigmáticos para todas as outras ciências.

Minayo (1994) afirma que a cientificidade não pode ser reduzida a uma forma determinada de conhecer o mundo. A autora menciona, inclusive, o fato de que as Ciências Sociais tenham buscado, durante muito tempo, a objetivação própria das Ciências Naturais, lembrando que tal procura 
pode até mesmo descaracterizar o que há de essencial nos fenômenos e processos sociais. De outra parte, não está absolutamente certo até hoje que as Ciências Naturais tenham atingido sua expressão adequada, a ponto de se tornarem paradigmáticas.

Em estudo que trata da pertinência da pesquisa qualitativa na área da saúde, Minayo (2000) diz que, em oposição ao positivismo, a Sociologia compreensiva propõe a subjetividade como fundante do sentido e constitutiva do social. Minayo também mostra que o avanço do debate sobre os critérios de cientificidade abalou profundamente as bases do positivismo. A autora cita Adorno, para quem o método positivista empírico tende a virar fetiche e a fetichizar o conhecimento, $\mathrm{e}$ insiste na idéia de que, se a ciência é dominante, nem por isso ela se torna conclusiva e exclusiva, pois os problemas sociais que ainda temos por enfrentar levantam muitas questões diante das quais a ciência continua sem respostas ou formulações.

Morin (1996b, 1996c) sustenta que a grande descoberta do século XX foi a de que a ciência não é o reino da certeza. A história seria feita de bifurcações, acasos, crises, e, portanto, haveria desordem em todos os niveis do universo. A ciência nova resultaria de transgressões lógicas, imprescindíveis à progressão do que o autor chama de "racionalidade aberta". Para Morin, estaríamos, hoje, no correr de uma revolução paradigmática, confrontados com o desafio da complexidade. Tudo está em relação, e o pensamento complexo - o verdadeiro pensamento - seria capaz de enfrentar a desordem e a incerteza do mundo. Renunciando à onisciência, o pensamento complexo adota mirantes, pontos de observação; assume que não é completo, e sim situado num tempo e num espaço.

Essa nova ordem científica foi também proposta pelos historiadores preocupados com o acessório, o acidental, o singular no curso dos acontecimentos. Burke (1992) refere-se à história vista de baixo, que leva em conta as opiniões e visões das pessoas comuns acerca de suas experiências de mudança social. Os teóricos da Nova História tomam o cotidiano como objeto de estudo e se preocupam com as vivências do homem comum, colocando-se novas perguntas sobre o passado e investigando outras fontes, além dos documentos escritos oficiais. Segundo Burke, a micro-história e a história da vida cotidiana constituiriam uma reação ao estudo das grandes tendências sociais, que retratariam uma sociedade sem face humana. 
A Nova História teria sido influenciada por três grandes movimentos de mudança social: o feminismo, a descolonização e a ecologia. Talvez por isso, Sharpe (1992) fale em ampliação dos limites das disciplinas cientificas tradicionais, abertura de novos campos de pesquisa, exploração da experiência histórica de outros sujeitos e agentes sociais, e busca de novos modelos interpretativos que não os já postos em prática pela História tradicional.

Para Levi (1992), a micro-história seria uma prática historiográfica de referências teóricas variadas e ecléticas, apresentando interfaces com as demais Ciências Sociais e exigindo uma revisão nos instrumentais e procedimentos de pesquisa. Uma marca relevante da micro-história seria o fato de que, nela, a observação de pormenores e detalhes poderia revelar fatos previamente não observados; assim, a tarefa do historiador seria partir de um conjunto de sinais significativos e tentar remetê-los a uma estrutura inteligivel, transformando ocorrências simples em cientificamente eloqüentes.

O caráter contingencial da história e seu tratamento pela ciência clássica também foram objeto de discussão de Certeau (1999, p. 165): "Incessantemente, a escritura científica, constituição de um lugar próprio, reconduz o tempo, este fugitivo, à normalidade de um sistema observável e legível. Assim, não há surpresas! Uma conservação dos lugares elimina essas voltas ruins".

Mas, prossegue Certeau (1999, p. 165, grifos nossos), essas voltas ruins

[...] retornam sempre, não apenas sub-reptícias e silenciosas, na própria atividade científica, não apenas nas práticas do dia-a-dia que, por não terem mais discurso, nem por isso deixam de ter existência, mas nas histórias também, tagarelas, cotidianas e astuciosas. Basta, para reconhecê-las aí, não se contentar (trabalho no entanto necessário) com examinar as suas formas ou estruturas repetitivas.

$\mathrm{O}$ historiador/cientista precisa ter em mente que um detalhe de circunstância pode fazer com que o quadro que lhe serve de suporte produza outros efeitos. Segundo Certeau (1999, p. 166), recitar uma história 
é "[...] jogar com esse elemento a mais, escondido no estereótipo feliz do lugar-comum".

A crise da ciência moderna também é citada em diversos trabalhos de Santos (2000a, 2000b, 2001). Para o autor, estamos em fase de transição paradigmática, rumo a uma ciência pós-moderna, caracterizada por um movimento de "desdogmatização". Nesse sentido, há que se aceitar a precariedade do conhecimento científico, que estaria inscrita no seu próprio caráter social e construído.

Essa postura iria de encontro ao saber científico hegemônico, que marginalizou outras formas de saber ao longo dos séculos. Isso resultou numa contradição: de par com um prodigioso desenvolvimento científico e tecnológico, acumulou-se muito conhecimento "sobre" o mundo, que, no entanto, se traduziu em pouca sabedoria "do" mundo, do homem consigo próprio, com os outros e com a natureza. $\mathrm{O}$ autor propõe que, no interior do paradigma pós-moderno, seriam posturas científicas adequadas a proximidade crítica, o envolvimento livre e a capacidade de espanto e revolta. O caos causado pelo aumento da contingência do mundo e do saber exige dos cientistas larga criatividade; antes atirado pela modernidade no "lixo da história", o caos retorna hoje na Epistemologia e nas Ciências Sociais como um horizonte ampliado de possibilidades, fazendo-nos "exercitar a perplexidade sem a sofrer".

A ciência pós-moderna teria também outras características:

- opera com galerias temáticas, mais do que com objetos estanques e rigidamente delimitados;

- não distingue o conhecimento científico do conhecimento vulgar;

- é relativamente imetódico, no sentido de que se constitui a partir de uma pluralidade metodológica;

- inventa novos contextos persuasivos e novos estilos e gêneros de escrita científica;

- admite a migração de conceitos e teorias entre os campos de saber, sendo, por isso, analógica e tradutora;

- mobiliza a imaginação e investe na qualidade e exemplaridade dos fenômenos estudados; 
- teria na incerteza a chave da compreensão do mundo, que, mais do que controlado, há de ser contemplado.

Esses atributos do novo pensamento científico podem fazer com que o conhecimento volte a ser uma "aventura encantada".

\section{A pesquisa qualitativa}

Informa Duarte (1998) que a seleção de dados pertinentes é uma característica básica da pesquisa qualitativa e que seu valor não reside neles mesmos, mas nos fecundos resultados a que podem levar. Por outro lado, $o$ rigor de uma pesquisa dessa natureza não se mede apenas por comprovações estatísticas, mas justamente pela amplitude e pertinência das explicações e teorias, ainda que estas não sejam definitivas e não sejam generalizáveis os resultados alcançados.

Para Luna (2000), numa pesquisa de cunho qualitativo, a escolha da técnica de análise tem a ver com a formulação do problema a ser investigado. Assim, a teoria deve tanto sugerir perguntas como indicar possibilidades de interpretação, servindo de referencial para os resultados que vão sendo observados.

Minayo $(1994,2000)$ diz que a pesquisa qualitativa responde a questões particulares, enfoca um nível de realidade que não pode ser quantificado e trabalha com um universo de múltiplos significados, motivos, aspirações, crenças, valores e atitudes. A autora defende que qualquer investigação social deveria contemplar uma característica básica de seu objeto, que é o aspecto qualitativo.

A pesquisa qualitativa foi e vem sendo largamente praticada por um certo ramo da Sociologia, preocupada não tanto em quantificar fatos e fenômenos, mas em explicar os meandros das relações sociais, considerando que a ação humana depende estreitamente dos significados que lhe são atribuídos pelos atores sociais. $O$ objeto das Ciências Sociais não se revela apenas nos números nem se iguala à sua própria aparência. Daí a necessidade de que os dados considerados qualitativos sejam abordados a partir de referenciais de coleta e interpretação de outra natureza. O potencial dos dados assim concebidos residiria na sua possibilidade de formular e reformular teorias e conhecimentos. 
Numa abordagem qualitativa, o pesquisador coloca interrogações que vão sendo discutidas durante o próprio curso da investigação. Ele formula e reformula hipóteses, tentando compreender as mediações e correlações entre os múltiplos objetos de reflexão e análise. Assim, as hipóteses deixam de ter um papel comprobatório para servir de balizas no confronto com a realidade estudada. Minayo destaca que é comum usar o termo "pressupostos" para falar de parâmetros básicos que permitem encaminhar a investigação empírica qualitativa.

Considerando a não-transparência e a não-evidência da realidade, a pesquisa qualitativa deve penetrar no interior de suas bordas, o que demanda do pesquisador abertura e flexibilidade para novas formulações, bem como a mobilização de conhecimentos integrados. De outra parte, no âmbito da pesquisa qualitativa, não se vê na subjetividade obstáculo à construção de conhecimentos científicos; antes, nesse tipo de abordagem, considera-se a subjetividade parte integrante da singularidade do fenômeno social (MINAYO, 2000).

Uma pesquisadora que vem dedicando muitas de suas reflexões à investigação qualitativa em educação é André. Em "A pesquisa no cotidiano escolar" (ANDRÉ, 2000), a autora salienta que, numa abordagem qualitativa, a teoria vai sendo construída e reconstruída no próprio processo de pesquisa, o mesmo se dando com as opções metodológicas, que vão sendo gradualmente explicadas e redefinidas. A análise ocorre paralelamente à observação, na medida em que o pesquisador seleciona aspectos que devem ser explorados e decide quais os que devem ser abandonados. Assim, as categorias analíticas podem derivar diretamente da teoria que respalda a pesquisa ou surgir do próprio conteúdo dos dados sob análise.

Em trabalho sobre a análise de dados qualitativos, André (1983) diz que estes nos permitem apreender o caráter complexo e multidimensional dos fenômenos educacionais, além de prestarem-se a captar os diferentes significados das experiências vividas e auxiliarem na compreensão das relações entre os indivíduos, seus contextos e ações. Uma marca importante dos dados qualitativos é também o fato de se constituírem em construtos válidos para a investigação de fenômenos de difícil quantificação. Nesse estudo, André ainda se refere a um constante transitar do pesquisador entre a realidade investigada e a teoria, num processo contínuo de inferências sobre o que os dados significam ou podem vir a significar, já que não se opera com 
um conjunto pré-especificado de categorias: as questões e os problemas iniciais servem de guia para a coleta e a análise dos dados, podendo surgir depois novas idéias, direções e mesmo novos objetos de investigação.

Em parceria com Lüdke (1986), André escreveu uma obra de referência sobre a pesquisa qualitativa. As autoras começam o trabalho mostrando a insuficiência da abordagem analítica experimental, pois, no caso de muitos fenômenos educacionais, é difícil isolar as variáveis envolvidas e apontar com segurança quais são as responsáveis por um determinado efeito. Com a pesquisa experimental, corre-se o risco de submeter a complexa realidade a um esquema simplificador de análise, sacrificando o conhecimento do fenômeno em favor da aplicação rigorosa de um esquema analítico. $\mathrm{Na}$ verdade, o fenômeno educacional situa-se num contexto sócio-histórico mais amplo, sofrendo, por isso, uma série de determinações. Assim, o pesquisador preocupa-se com o processo mais do que com o produto; a ele interessa menos encontrar evidências que comprovem hipóteses predefinidas e mais formar e consolidar abstrações a partir da inspeção dos dados. Isso significa que o pesquisador, interrogando os dados, constrói novos conhecimentos sobre o fato pesquisado, os quais irão se somar à teoria já acumulada e conhecida. ${ }^{2} \mathrm{O}$ fato de não haver hipóteses prévias de trabalho não significa que não haja um quadro teórico de referência que oriente a coleta e a análise dos dados, ou que a pesquisa seja desprovida de rigor. O procedimento do pesquisador na abordagem qualitativa é um pouco diferente: atento à multiplicidade de dimensões de uma determinada situação ou problema, e após a análise dos dados, ele lança possibilidades de explicação da realidade, tentando encontrar princípios subjacentes ao fenômeno estudado e situar as suas descobertas num contexto mais amplo; trata-se de um esforço de construção ou estruturação de um quadro teórico dentro do qual o fenômeno possa ser interpretado e compreendido.

A diversidade de pontos de vista que pode decorrer desse procedimento não é vista como limitação. Considera-se que a exigência de consenso é típica dos esquemas clássicos de pesquisa, e, nesse sentido, uma possível categorização dos dados não esgota a análise - é preciso, depois dela, fazer um esforço de abstração, ultrapassar os dados em si mesmos, tentar estabelecer conexões e relações que tornem possível a proposição de novas explicações e interpretações do fato estudado. 
Ainda a respeito do procedimento na pesquisa qualitativa e da interpretação dos dados, encontramos um elevado grau de consenso entre os autores consultados, além de Lüdke e André (1986). Deslandes (1994) diz das hipóteses que elas se constituem numa tentativa de criar indagações a serem verificadas na investigação, numa forma de diálogo entre o olhar do pesquisador e a realidade investigada, num conjunto de afirmações provisórias a respeito de um determinado problema. Para a autora, as hipóteses podem ser formuladas a partir de fontes as mais diversas (observações, teorias, resultados de outras pesquisas...), inclusive a própria intuição do pesquisador.

Para Gomes (1994), é importante articular as conclusões que vão surgindo dos dados concretos com conhecimentos mais amplos e abstratos. As finalidades da análise seriam basicamente três:

- estabelecer uma compreensão dos dados coletados;

- confirmar ou não os pressupostos da pesquisa e/ou responder às questões formuladas;

- ampliar o conhecimento sobre o assunto pesquisado, articulando-o ao contexto cultural do qual faz parte.

Diz ainda o autor que a análise final permite estabelecer articulações entre os dados e as referências teóricas, respondendo às questões da pesquisa com base em seus objetivos. Entretanto, o produto final da análise deve ser sempre encarado de forma provisória e aproximativa.

A provisoriedade dos resultados de uma pesquisa também aparece nas considerações de Alves (2000), para quem o cientista é um "caçador do invisivel". Diz o autor que os mesmos fatos podem adquirir sentidos totalmente diferentes, dependendo do contexto explicativo em que são colocados. O que o cientista deve objetivar não é um rol de fatos e resultados, mas sua integração num esquema teórico explicativo.

Esse percurso também está destacado em Certeau (1999). Segundo ele, as práticas de pesquisa, volta e meia, exacerbam e desencaminham nossas lógicas, mas o que parece importante é o trabalho de ultrapassagem operado pela insinuação do ordinário em campos científicos constituídos; o caminho a percorrer seria, pois, o de reconduzir as práticas e linguagens cientificas para a vida cotidiana, ainda que esse retorno implique o paradoxo 
de representar um exilio em relação às disciplinas científicas, cujo rigor se mede pela estrita definição de seus limites.

Cavalcanti e Moita Lopes (1991) apontam como características da pesquisa qualitativa:

- ser uma pesquisa eminentemente exploratória;

- não exigir hipóteses prévias nem categorias rígidas de análise;

- permitir ao pesquisador tomar decisões ao longo do estudo;

- possibilitar uma teorização calcada nos dados;

- preocupar-se com o particular.

Mason (1997) destaca, na pesquisa qualitativa, o seu poder interpretativo, o emprego de métodos flexíveis e sensíveis ao contexto, e o tratamento dos fenômenos, ao mesmo tempo, em sua complexidade e detalhe. Já Monteiro (1991) chama a atenção para os limites das pesquisas restritas a uma simples descrição de situações e considera como aspectos importantes da pesquisa qualitativa: a interpretação de dados predominantemente descritivos, a supremacia do processo sobre o produto e a atenção especial conferida aos significados dos processos sociais.

Para encerrar este item, destacamos o artigo de Marques (1997). Segundo o autor, as opções metodológicas no âmbito da investigação qualitativa não constituem um princípio em si, mas são fortemente afetadas pelo tipo de problema que o pesquisador se dispõe a enfrentar. Desse modo, a questão fundamental não é o emprego deste ou daquele método ou a consideração deste ou daquele dado, mas, sim, quais problemas se colocam como desafio ao pesquisador. A decisão sobre um método ou técnica depende, portanto, das questões primeiras da pesquisa, da natureza mesma do problema investigado. Marques deixa claro, no entanto, que não propõe um mero sincretismo metodológico diante da complexidade dos fenômenos educacionais. Ele sugere, sim, articulações e complementações com vistas a superar os limites de cada método e fornecer interpretações mais abrangentes do fato em estudo.

\section{O quantitativo e o qualitativo: inter-relações}

Uma discussão necessária no quadro da pesquisa qualitativa é aquela relativa ao valor do dado quantitativo nesse tipo de empreendimento 
científico. Indursky (1990), em pesquisa sobre a ocorrência de estruturas passivas no documento que ficou conhecido como Relatório Pinotti ${ }^{3}$, afirma que, thos estudos do discurso, não são apenas os dados predominantes que devem ser analisados. Ela acha que, ao contrário, dados numericamente pouco expressivos não devem ser desqualificados, uma vez que podem produzir efeitos de sentido significativos no funcionamento do discurso em análise, isto é, enquanto dados salientes revelam a regularidade de um funcionamento discursivo, dados quantitativamente pouco expressivos podem indicar um funcionamento que, mesmo não sendo regular, está instaurado e, conseqüentemente, participa dos processos semânticos do discurso.

O que parece relevante é que as análises quantitativas ou qualitativas não se justificam por si mesmas. Elas adquirem dimensão e sentido diferentes em função do quadro em que se inserem ou do paradigma que as prioriza ou não (SÁNCHEZ GAMBOA, 2000). De fato, há problemas e temas para cujo tratamento os métodos quantitativos são úteis e até mesmo indispensáveis, embora, em pesquisa qualitativa, não haja, em princípio, grande preocupação com amostragens e quantificações. Triviños (1987), ao se reportar aos dados estatísticos, afirma que é possível aproveitar as informações que estes traduzem, no sentido de realizar interpretações mais amplas e abrangentes dos fatos em discussão. Talvez porque, como bem salientam Laville e Dionne (1999), o que é significativo no plano estatístico não o é necessariamente nos planos psicológico e social.

No prefácio à obra de Certeau (1999), Luce Giard diz que os dados numéricos têm validade e pertinência conforme as condições de sua coleta: tratados manualmente ou submetidos a um tratamento sofisticado por alguma máquina, os dados continuam sendo o que são no momento de sua produção como tais; assim, sua qualidade e informatividade são proporcionais às dos procedimentos para obtê-los e construir as categorias que organizam a produção. Após o prefácio, o próprio Certeau (1999) tece suas considerações acerca da estatística como técnica de pesquisa. Diz o autor que a força dos cálculos estatísticos repousa em sua capacidade de dividir a realidade, mas é precisamente essa fragmentação analítica que pode nos fazer perder de vista aquilo que os dados supostamente representam. A estatística se vale dos procedimentos de classificação, cálculo e tabulação de unidades, fazendo-o em função de categorias e taxionomias que lhe 
são próprias. Assim, a enquete estatística só nos permite encontrar o homogêneo.

No caso de Certeau (1999), que estudou particularmente as astúcias e táticas do consumidor, a estatística não daria conta do fraseado devido à bricolagem, da inventividade artesanal, da discursividade que combina os elementos do cotidiano. A análise estritamente quantitativa deixaria fora de seu campo a "proliferação das histórias" e as "operações heterogêneas" que compõem os patchworks da vida diária; esse tipo de análise não capta o "movimento sub-reptício e astucioso" do "fazer com", porque contabiliza o que é usado, mas não as maneiras de utilizar os objetos de consumo.

Santos (2001) critica a idéia subjacente aos modelos matemáticos de análise de que conhecer equivale a quantificar. Para o autor, dentro do paradigma clássico, o rigor científico de uma análise era aferido pelo rigor das medições mesmas. Esse modo de proceder terminou por desqualificar aspectos intrínsecos do objeto de estudo que, eventualmente, poderiam ter um importante valor analítico. Em lugar disso, imperam as quantidades em que o objeto se possa traduzir, de modo que o que não era quantificável passou a ser encarado como cientificamente irrelevante.

Modernamente, depois de um periodo em que as abordagens quantitativa e qualitativa eram vistas de forma dicotômica, muitos epistemólogos e pesquisadores vêm propondo que as duas se articulem em benefício das análises daí resultantes. Gonsalves (2001) caracteriza a abordagem quantitativa como aquela em que o pesquisador procura explicar as causas do fenômeno estudado, por meio de medidas objetivas, estatísticas e testes de hipóteses. Já a abordagem qualitativa teria como marca a compreensão e interpretação dos fenômenos, considerando os significados que os sujeitos atribuem às suas práticas. A autora sugere que o dualismo seja superado e que cada uma dessas abordagens seja empregada em níveis diferentes de profundidade, conforme a natureza dos dados em jogo.

O mesmo propõe Thiollent (1984), que julga serem as preocupações muito diversificadas no campo da metodologia da pesquisa social, a ponto de não se reduzirem a uma oposição entre quantidade e qualidade. Thiollent acha que uma articulação entre ambas seria a postura científica mais satisfatória, mas salienta que, dependendo do assunto ou da abrangência da observação, certas pesquisas seguem sendo principalmente qualitativas ou quantitativas. 
Para Minayo (1994), a diferença entre os aspectos quantitativo e qualitativo é de natureza. No caso da pesquisa social, a abordagem qualitativa aprofundaria a investigação do universo dos significados das ações e relações humanas, um lado não perceptível diretamente e não captável em equações, médias e estatísticas. A pesquisa qualitativa teria sido bastante reforçada no âmbito da chamada Sociologia compreensiva, exatamente porque aí não havia uma preocupação forte com a quantificação dos fenômenos, mas, sim, com a compreensão/explicação da dinâmica das relações sociais, as quais, por sua vez, são depositárias de crenças, valores, atitudes e hábitos. De todo modo, os dados quantitativos não se opõem aos qualitativos; antes, eles se complementam, pois a realidade abrangida por ambos é dinâmica. $\mathrm{Na}$ obra $\mathrm{O}$ desafio do conbecimento: pesquisa qualitativa em saúde, Minayo (2000) explicita sua opção pela dialética como caminho metodológico de pesquisa e diz que, nessa abordagem, quantidade e qualidade são inseparáveis e interdependentes, sendo cada uma elemento da compreensão do todo.

Num procedimento eminentemente quantitativo, uma vez definida a população da pesquisa, busca-se um critério de representatividade numérica que permita a generalização dos conceitos teóricos que se quer testar. No procedimento qualitativo, por outro lado, o cientista preocupa-se menos com a generalização e mais com o aprofundamento e a abrangência da compreensão; os dados qualitativos permitiriam trazer à tona o subjetivo e o objetivo, os atores sociais, os fatos e seus significados, a ordem e os conflitos.

Os pesquisadores que contestaram o quantitativismo sociológico não enfocaram especificamente suas técnicas, ou seja, eles continuavam valorizando as análises multivariadas, contextuais e de correlação, considerando-as poderosos e reconhecidos instrumentos de pesquisa, sobretudo em se tratando de dados aglomerados e indicadores sobre a coletividade. A crítica estava, realmente, no fato de se restringir a realidade social apenas ao que pudesse ser observado e quantificado (MINAYO, 2000).

Marques (1997) alude a Florestan Fernandes, lembrando que, nas Ciências Humanas, que lidam com fenômenos cuja interpretação exata nem sempre depende da quantificação, tem sido adequado defender o ponto de vista de que ambas as modalidades de explicação são necessárias e devem igualmente ser desenvolvidas dentro de seus limites. Pondera ainda o autor 
que, se, por um lado, a abordagem quantitativa é parcial e seus dados podem ser pobres de significação, por outro lado, os dados quantitativos podem fornecer informações importantes para a análise e a interpretação de uma certa realidade, pois permitem sugerir hipóteses qualitativas acerca de fatos quantitativamente indicados.

No tocante à avaliação educacional propriamente dita, Marques crê que as pesquisas quantitativas "colhem um instantâneo" da realidade, focam apenas o final da linha (os resultados); contudo, como dados globais e numa perspectiva dialética, em que quantidade e qualidade se interpenetram, os resultados podem perfeitamente nos conduzir para o interior das escolas, no sentido de buscar novas possibilidades de interpretação e explicação para eles.

\section{Os dados e o procedimento analítico}

Numa pesquisa de cunho qualitativo, os dados não são evidentes. ${ }^{4}$ Segundo Gomes (1994), a construção dos dados se faz a partir dos questionamentos que formulamos sobre eles. Essa opinião é compartilhada por Lüdke e André (1986), que afirmam que os dados não se revelam diretamente aos olhos do pesquisador. $\mathrm{Na}$ verdade, é preciso selecionálos, e os mais importantes são aqueles que melhor ajudam a compreender e interpretar o fenômeno estudado. Desse modo, os dados devem ser relevantes para responder as questões do pesquisador, e os métodos de codificação dependerão da natureza do problema levantado, do arcabouço teórico e de questões específicas da pesquisa.

A construção do dado faz com que a seleção já seja parte do procedimento analítico (DUARTE, 1998). Todo dado e todo fato já são interpretações, maneiras de construirmos a relevância da realidade (MINAYO, 2000). Nesse sentido, o que importa numa construção de corpus não é o seu tamanho: a representatividade, a pertinência e a qualidade da amostra têm mais a ver com a possibilidade que ela abre de abranger várias de suas dimensões (DUARTE, 1998; DESLANDES, 1994).

A respeito do procedimento metodológico, Luna (2000) considera-o um conjunto de passos que geram dados relevantes. O pesquisador recorta a realidade, selecionando as informações necessárias e significativas. Faz-se necessário explicitar os meios de transformação dessas informações em 
dados, e dessa operação vão depender as respostas possíveis às questões da pesquisa. Por isso, para Luna, a metodologia não se reduz a procedimentos técnicos de coleta de dados e informações. Deslandes (1994) também é da mesma opinião; ela acha que, mais do que uma descrição formal de métodos e técnicas a serem utilizados, a metodologia indica as opções e a leitura operacional que o pesquisador faz do quadro teórico. Já Minayo (1994) propõe que, no tratamento dos dados, seja feita uma teorização, de modo a produzir confrontos e cotejos entre as abordagens teóricas anteriores ao estudo e o que ele aponta como contribuição.

Coracini (1991) diz que a opção por um caminho metodológico nos estudos da linguagem vai depender das concepções de linguagem/discurso em jogo. Depois de apresentar nove concepções, a autora agrupa-as em dois grandes blocos, indicando o princípio metodológico que rege cada um:

- de um lado, teríamos a concepção de linguagem que a toma como processo simbólico situado num contexto interativo e comunicacional; metodologicamente, os partidários dessa concepção iriam do texto em direção à situação de enunciação; o pesquisador preocupa-se com os enunciados como produtos e buscaria neles vestígios da situação extralingüística em que ocorrem; essa visão pressupõe uma separação entre o texto e seu contexto de produção;

- de outro lado, teríamos a concepção de linguagem como discurso, efeito de sentidos entre locutores; o procedimento metodológico consistiria em partir das representações das condições de produção do discurso inseridas numa dada formação discursiva (que, por sua vez, se insere numa formação ideológica), para compreender o texto e os procedimentos nele postos em prática; aqui, a preocupação maior é com o processo, na medida em que o analista busca explicar as condições que possibilitaram a emergência daquela (e não de outra) realização lingüística.

Certeau (1999) aponta, como inconveniente do método científico tradicional, a abstração dos dados e documentos do seu contexto histórico. Embora esse recorte seja condição do sucesso do paradigma das Ciências Exatas e Naturais, no caso dos estudos da linguagem, ele elimina as operações dos locutores, realizadas em circunstâncias sócio-históricas 
particulares; apagam-se, assim, as práticas lingüísticas cotidianas e o espaço em que ocorrem, para que as práticas científicas sejam exercidas em seu campo próprio, sem turbulências. Daí a proposta de Certeau (1995) de um entrecruzamento de discursos e métodos, no sentido de tornar possível captar cada momento histórico na multiplicidade de seus componentes e na contradição de seus conflitos.

Proposta semelhante é lançada por Santos (2001). Para ele, cada método é uma linguagem, e a realidade responde na língua em que é perguntada. Então, só uma constelação de métodos permitiria "[...] captar o silêncio que persiste entre cada língua que pergunta", e o contexto de crise e revolução científica seria favorável a essa pluralidade de métodos, a qual resultaria de uma transgressão metodológica.

Ainda com relação à definição do corpus em investigações do tipo indiciário, cabe levar em conta alguns pressupostos acerca da pesquisa em Educação sugeridos por Pérez Gómez (1998). Inicialmente, concordamos com o autor quanto ao fato de que o caráter subjetivo e complexo dos fenômenos educativos requer uma metodologia de investigação que respeite sua natureza. Com efeito, tais fenômenos têm um caráter inacabado e são marcados por sua dimensão criativa, autotransformadora e aberta à mudança. Daí que a natureza do problema a ser estudado é que deve determinar as características das proposições, dos processos, das técnicas e dos instrumentos metodológicos utilizados, e não o contrário.

Outro aspecto importante é que, no âmbito da semiótica dos fatos educativos, a relação entre o significante observável e o significado latente é indeterminada e polissêmica. $\mathrm{O}$ objeto da investigação educacional é um complexo sistema simbólico, que se dá num espaço institucional determinado, de modo que o conteúdo e as formas de pensar, sentir e agir dos sujeitos envolvidos são necessariamente afetados por essas redes moventes de significados. Nesse sentido, os procedimentos de pesquisa devem possibilitar a indagação da produção e troca de significados e a interpelação problematizadora dos dados (mais do que propriamente a sua divulgação).

Pérez Gómez (1998) denomina esse procedimento investigativo, em virtude de seu aspecto simbólico, de enfoque interpretativo. Nele, o pesquisador segue, como estratégia de trabalho, tanto a lógica indutiva quanto a dedutiva (e a ambas acrescentaríamos a abdutiva), de modo que 
haja interconexões entre teorias, hipóteses de trabalho, dados, enfoques e acontecimentos. O pesquisador não se limita, em princípio, a comprovar hipóteses, mas amplia seus objetivos de modo a apreciar os acontecimentos em sua complexidade constitutiva, indagando sobre eles com liberdade e flexibilidade, elaborando descrições e abstrações dos dados, estas sempre provisórias e tomadas como possibilidades de busca e trabalho.

O enfoque interpretativo caracteriza-se por ser progressivo: ao longo do processo de investigação, vão sendo produzidas sucessivas definições de análise e focalização dos dados, conforme se evidencia a sua relevância para o debate sobre o tema em questão. Em tese, todos os resultados, previstos ou não, devem ser levados em conta como informações potencialmente úteis para interpretar e compreender a complexidade da realidade educacional.

Expondo os traços do enfoque interpretativo, Pérez Gómez (1998, p. 106) afirma:

Os acontecimentos anômalos e imprevistos, as variáveis ou fatores estranhos são sempre bem-vindos, já que o objetivo prioritário dessa estratégia não é construir teorias consistentes e organizar sua comparação, mas mergulhar na complexidade do mundo real do caso concreto que queremos estudar, bem como refletir sobre as observações, os registros, as informações e as perspectivas dos envolvidos [...]. Tais fatos emergentes são ocasiões "de ouro" para compreender o funcionamento da realidade, já que alteram a rotina e põem a descoberto conflitos, interesses, necessidades e comportamentos, habitualmente ocultos e soterrados. ${ }^{5}$

Dentro dessa perspectiva de trabalho, não é o caso de privilegiar um método específico de análise e discussão dos dados. Estes podem ser apreciados ora global, ora localizadamente; ora quantitativa, ora qualitativamente; ora com ênfase no aparente, ora com ênfase no latente, numa espécie de pluralismo metodológico e analítico que julgamos pertinente quando se trata de apreciar a produção discursiva no âmbito da escola.

Passemos agora a examinar a questão dos dados e do procedimento analítico no âmbito da análise do discurso (AD). Tradicionalmente, os 
estudos lingüísticos voltaram-se para a análise da língua como sistema fechado, governado por regras e sistematicidades. Tal perspectiva, criada a partir do corte epistemológico de Saussure, fez da fala o lugar do acaso, da circunstância, da heterogeneidade e, portanto, algo fora do escopo da Lingüística. A AD amplia a possibilidade de análise da linguagem, definindo como seu objeto o discurso, tomado como prática sócio-histórica, trabalho simbólico, parte da produção social mais geral (MAINGUENEAU, 1996, 1997; ORLANDI, 1988). Assim, procura descrever não o sistema abstrato da língua ou o seu produto, mas os processos de constituição do fenômeno linguístico e dos sentidos ai engendrados. É uma forma de abordagem da linguagem que releva sua dimensão de acontecimento na estrutura (PÊCHEUX, 1997b).

Vale destacar, todavia, que, apesar de o discurso ser, de fato, o objeto da $\mathrm{AD}$, o lingüístico intervém nele como pressuposto. Como bem lembra Orlandi (1998b, p. 17), “[...] os processos discursivos são a fonte dos efeitos de sentidos e a língua é o lugar material em que esses efeitos se realizam". Ainda em termos do objeto, temos que o interesse da $\mathrm{AD}$ se desloca da organização para a ordem da língua, uma vez que esta é tomada como sistema significante em sua relação com a história, considerada em sua materialidade simbólica (ORLANDI, 1998b).

Tomado o discurso como palavra em movimento, a AD procura, para além das dicotomias da Lingüística clássica, explicar o funcionamento dos discursos, tirando proveito de sua fluidez, da alteridade do sujeito, da opacidade do sentido. Não se trata, portanto, de buscar "o" sentido do texto, mas de explicar como os sentidos são produzidos na e pela materialidade da língua. Eis a razão pela qual Pêcheux, na Análise automática do discurso, propõe o deslocamento da noção de função para a de funcionamento: a tarefa da $\mathrm{AD}$ seria explicar como os sentidos são constituídos na instância de discurso, conhecer os mecanismos através dos quais se põe em jogo um determinado processo de significação, enfim, compreender como um objeto simbólico produz sentido. Esses objetivos convergem para a inter-relação do lingüístico com o ideológico na constituição tanto dos sujeitos como dos sentidos. Isso, por sua vez, implica remeter o discurso às suas condições de produção, à memória que o determina, à formação discursiva que o torna possivel (FOUCAULT, 1998; ORLANDI, 1999). Essa remissão é que permite compreender o processo de produção dos sentidos. A dimensão 
ideológica daria conta, ainda, das formações imaginárias constitutivas dos sentidos e dos sujeitos (PÊCHEUX, 1997a; ORLANDI, 1997).

Aceito o pressuposto de que a linguagem não é transparente, a análise deve dar conta não "do" sentido do texto, mas de como o texto produz sentidos, levando em consideração, ao mesmo tempo, o processo de constituição do sujeito e a materialidade do sentido (o "teatro da consciência" de Pêcheux). É imperioso, para o analista de discurso, considerar os processos e as condições de produção da linguagem pela análise da relação estabelecida pela língua com os sujeitos que a falam e as situações em que falam (ORLANDI, 1999). É assim que, na $A D$, se relacionam linguagem e exterioridade.

A AD produziu um deslocamento importante, se comparada com as teorias de caráter conteudista - em lugar da habitual pergunta " $O$ que este texto quer dizer?", ela pergunta: "Como este texto significa?". Para tanto, é necessário:

- remeter o texto ao discurso;

- explicitar a referência deste a uma formação discursiva;

- relacionar a formação discursiva com a formação ideológica de que deriva. Por isso, pode-se afirmar que a $\mathrm{AD}$ não visa ao texto em si como objeto final de sua descrição, mas como a unidade que lhe permite ter acesso ao discurso, ou seja, a atenção do analista deve se voltar para o modo como o discurso se textualiza, e não para a superfície lingüística do texto.

Em $\mathrm{AD}$, tomam-se como dados as marcas do discurso, que, conforme Indursky (1990), instauram modalidades diversas de funcionamento discursivo e apontam para diferentes relações que o falante estabelece com a linguagem e com esse funcionamento. Referindo-se às marcas, Orlandi (1994) afirma que elas não são auto-evidentes, não valem pelo seu aspecto empírico ou formal, ou seja, elas não dizem, em si mesmas, nada sobre as regularidades, as propriedades ou as características de um discurso. As marcas são pistas, e a relação entre elas e o que significam é indireta; por isso, a $\mathrm{AD}$ visa à compreensão de como as marcas acionam certos processos de significação.

Trata-se, na verdade, de um percurso analítico que vai da superfície lingüística (material bruto) para o objeto discursivo. Esse é justamente o 
trabalho de análise da materialidade lingüística: compreender como se diz, quem diz, em que circunstâncias, a partir de que lugar social, etc. (como processo de enunciação em que o sujeito se marca no que diz), para, em seguida, compreender o modo como o discurso pesquisado se textualiza/ funciona, observada a relação entre diferentes superfícies lingüísticas em face do mesmo processo discursivo (ORLANDI, 1999).

Em outro trabalho (ORLANDI, 1998a), a mesma autora sustenta que o material a ser investigado se organiza em função de alguns princípios teóricos, razão pela qual o corpus é instável e provisório, e sua exaustividade não deve ser considerada em relação ao material empírico propriamente dito, mas em relação aos objetivos e à temática da pesquisa.

$O$ foco do analista, em $A D$, não recai sobre os aspectos formais do texto, mas sobre a materialidade lingüístico-histórica do discurso. Cabe reconhecer, nessa materialidade, os indícios, vestígios ou pistas dos processos discursivos aí inscritos, buscando explicitar os mecanismos que remetem a língua à história para que a primeira signifique. Daí a relevância do conceito de recorte, já que não há discursos fechados em si mesmos, mas processos discursivos dos quais se pode recortar e analisar estados e modos de funcionamento (ORLANDI, 1999).

É necessário considerar o modo como as marcas se manifestam, relacioná-las com o conjunto de propriedades do discurso (PECCHEUX, 1997b; ORLANDI, 1998a). Se, por um lado, as marcas têm a ver com a organização do discurso, a propriedade, por outro lado, remete ao discurso em sua relação com a exterioridade, com a situação de produção, a qual envolve os aspectos institucionais, culturais, ideológicos, etc., da produção discursiva. A relação entre o discurso e esse "exterior" é também indireta, e não automática. Uma noção muito produtiva em $\mathrm{AD}$, para dar conta das marcas e propriedades fora de uma abordagem formal, é a de forma material (forma inscrita na história para produzir sentido).

\section{O paradigma indiciário}

O paradigma indiciário pode ser considerado um tipo específico de pesquisa qualitativa. A seguir, ele será explicitado, e serão mostradas as razões pelas quais ele pode ser considerado como bastante adequado no tratamento de dados da pesquisa educacional no campo da linguagem. 
Lüdke e André (1986), discutindo o estudo de caso como estratégia de investigação qualitativa, dizem da importância de atentar para o maior número possível de elementos presentes na situação estudada, pois um aspecto supostamente trivial pode ser essencial para uma melhor compreensão do tema da pesquisa, ou seja, certas informações e observações, aparentemente isoladas e discrepantes, podem vir a se constituir em elementos importantes na elucidação das questões levantadas no e pelo estudo em andamento. Quando se trata de um estudo de caso, o pesquisador preocupa-se em compreender uma instância ou manifestação singular do fenômeno; nessa situação, o objeto de estudo é tratado como único, uma representação singular da realidade, reconhecida como multidimensional e historicamente situada. Quanto ao fato de o estudo de caso ser ou não típico, esta é uma questão inadequada, já que cada caso é tratado como tendo um valor intrínseco em si mesmo.

A singularidade e a eventual importância de certos dados também foram objeto de discussão de André (1983). É possível, conforme a autora, que alguns dados de pesquisa contenham aspectos, observações, comentários e características únicas, mas extremamente relevantes para uma apreensão mais abrangente do fenômeno estudado. Diante dessa possibilidade, André põe em destaque a importância, ao lado do quadro teórico de referência, da subjetividade e da intuição do pesquisador.

O paradigma indiciário foi proposto pelo historiador italiano Carlo Ginzburg. Ele partiu da idéia de que a História tradicional ocultou, deixou de lado ou simplesmente ignorou uma série de detalhes que, ainda que considerados casuais ou de pequena importância, eram relevantes para a explicação dos fatos históricos. Nesse sentido, Ginzburg tentou valorizar as idéias, crenças e percepções dos individuos ou de determinados grupos sociais diante dos acontecimentos históricos (GINZBURG, 1998).

No texto "Sinais: raízes de um paradigma indiciário", da coletânea Mitos, emblemas e sinais:morfologia e História, Ginzburg (1999) ressalta a pertinência de trabalhar em História com um novo método interpretativo centrado nos resíduos, nos dados marginais que possam, eventualmente, ser considerados reveladores. O historiador poderia, nessa perspectiva, operar com pistas, sintomas e indícios, e não apenas com fatos explícitos. Essas pistas permitiriam até captar aspectos da realidade, inatingiveis através das formas clássicas de investigação. 
Ginzburg informa que o paradigma indiciário despontou nas Ciências Humanas no século XIX, mas que suas raízes são mais antigas. O que caracteriza esse saber é a possibilidade de o pesquisador, a partir de dados aparentemente negligenciáveis, remontar a uma realidade complexa, não experimentável diretamente. Esse procedimento já era seguido pelos caçadores, que viviam experiências de decifração de pistas, lendo, em sinais quase imperceptíveis, uma série coerente de eventos. No seu rastro, desenvolveram-se várias disciplinas apoiadas na decifração dos mais diversos tipos de signos. Subjacente a todas elas, está o princípio de que a realidade não é transparente.

Apesar do "vasto território" e do valor inegável do saber conjectural, o paradigma indiciário permaneceu desprestigiado diante dos modelos clássicos de conhecimento. Assim, várias disciplinas indiciárias ficatam fora dos critérios de cientificidade estabelecidos pelo paradigma galileano. Essas disciplinas são prioritariamente qualitativas e tomam por objeto casos, situações, documentos individuais e particulares e que, justamente por isso, conduzem a resultados dotados de um alto grau de casualidade. Como isso era considerado um ponto frágil das disciplinas indiciárias, elas passaram a seguir a mesma tendência antiantropocêntrica e antiantropomórfica das Ciências Naturais (isso porque, dentro do paradigma galileano, quanto mais os traços individuais eram considerados pertinentes, menor seria a possibilidade de elaboração de um conhecimento rigoroso). Como exemplo, Ginzburg cita a Filologia e a Crítica Textual, que foram operando, progressivamente, uma drástica redução de certos elementos pertinentes ao objeto de estudo: o texto foi se desmaterializando, depurando-se de suas referências sensíveis como a oralidade, a gestualidade e o próprio caráter físico da escrita.

De modo oposto, o paradigma indiciário se apóia na idéia de que, sendo a realidade opaca, alguns de seus sinais e indícios permitiriam "decifrá-la", no sentido de que indícios mínimos podem ser reveladores de fenômenos mais gerais. Tal princípio foi sendo adotado em vários campos do conhecimento, modelando significativamente as Ciências Humanas. Estas, no entanto, não se livraram do dilema entre um estatuto científico frágil para chegar a resultados relevantes e um estatuto científico forte para chegar a resultados de pouca relevância, até concluírem que o rigor científico do paradigma galileano era indesejável para as disciplinas que elegiam como seu 
objeto a experiência cotidiana ou situações em que a unicidade e o caráter insubstituível dos dados eram de extrema importância para a pesquisa.

Assim, Ginzburg usa a expressão "rigor flexível" para caracterizar o paradigma indiciário, no interior do qual não se trabalha com regras explícitas, formalizadas ou preexistentes, mas com o faro, o golpe de vista, a intuição. No caso da História, esse paradigma funcionaria como uma "sonda" para "perscrutar" um conjunto de fatos inacessiveis aos instrumentos usuais do conhecimento histórico.

Pimentel (1998) utilizou o paradigma indiciário em uma investigação sobre a produção de textos na escola. A autora partiu da hipótese de que elementos constitutivos da experiência anterior dos alunos com a linguagem são reconstruidos nos textos que eles escrevem; procurou, então, verificar nesses textos indícios de leituras anteriores, realizadas dentro e fora da escola. Para tanto, valorizou detalhes, elementos aparentemente residuais que poderiam revelar aspectos importantes da trajetória dos alunos até chegar à versão final do texto. Nessa pesquisa, foi reconhecida a relevância de dados singulares, episódicos e residuais, pois, através deles, se poderia chegar ao que não era aparente.

Um aspecto importante do paradigma indiciário que foi destacado por Pimentel é que o indício se constitui como um dado à luz de hipóteses iniciais, e o pesquisador se põe num movimento entre a hipótese e os dados, com vistas à construção de explicações para os fenômenos observados. Considerando, então, que o aluno deixa pistas na escrita, Pimentel procurou, a partir de sua hipótese, interpretar essas pistas, identificando nelas marcas da relação do sujeito com a linguagem em geral e com a leitura em particular.

Utilizando-se também do paradigma indiciário, Duarte (1998) fez um estudo sobre a produção textual de vestibulandos. No caso, tratava-se de candidatos que deveriam produzir uma redação a partir da leitura de pequenos trechos relativos ao assunto a ser desenvolvido, e tais trechos expressavam diferentes pontos de vista sobre a questão. A hipótese de Duarte era a de que as redações trariam marcas de intertextualidade reveladoras dos diferentes procedimentos de leitura empregados pelos vestibulandos.

Também aqui temos um trabalho em que o olhar do pesquisador se voltou para o dado singular, para o detalhe significativo, interpretado 
por meio de procedimento abdutivo de investigação: parte-se de uma base teórica em direção aos dados, os quais podem, por sua vez, levar a modificações na teoria, e assim por diante. Duarte esclarece que a abdução decorre da observação atenta dos dados, o que deve ser seguido de uma seleção das melhores hipóteses dentre as várias que se tomam como possíveis explicações para o que foi observado. É possível, também, que a consideração dos próprios fatos sugira a hipótese explicativa, num trabalho de realização de novas checagens dos dados a cada hipótese levantada. ${ }^{6}$ Nesse tipo de abordagem, o pesquisador não há de esperar a repetição de certas ocorrências, mas deve interpretá-las no que elas têm de relevante ou significativo para explicar aquilo que se quer compreender. A investigação de Duarte deixa claro que o dado singular pode ser extremamente revelador de um objeto tão complexo como é a linguagem. Articulando o paradigma indiciário com uma concepção discursiva de linguagem, Duarte pôde encontrar explicações consistentes para os diferentes tipos de leitura realizados pelos vestibulandos, expressos em suas produções textuais.

A respeito da singularidade de certas ocorrências encontradas quando se investiga a relação entre sujeito e linguagem dentro da escola, diz Duarte (1998, p. 62):

Às vezes, um dado singular não tem aparentemente uma explicação para sua ocorrência; é idiossincrático, diferente e, muitas vezes, estranho. $\mathrm{O}$ trabalho do analista será o de justificar sua ocorrência, buscando compreender os fenômenos que estão por trás dele. Para isso, é importante que [...] a maneira como determinado dado possa ter aparecido seja objeto de reflexão para o analista.

$\mathrm{Na}$ obra Cenas de aquisição da escrita: o sujeito e o trabalbo com o texto (ABAURRE; FIAD; MAYRINK-SABINSON, 1997a), as autoras mostram os resultados de uma pesquisa integrada que empreenderam com base no paradigma indiciário. Inicialmente, elas esclarecem o que tomam por "dado singular": trata-se daquele dado que, efetivamente, é revelador do que se busca conhecer. Além disso, discutem a validade da adoção do modelo indiciário para a análise de fatos concernentes à relação entre sujeito e linguagem, em comparação com o paradigma galileano. Citando Quartarolla (1994), põem em relevo o papel da intuição do pesquisador na observação 
e na análise do dado singular, com vistas à formulação de hipóteses plausíveis para explicar aspectos da realidade não captáveis diretamente, mas recuperáveis exatamente através de sintomas e indícios.

A atenção das pesquisadoras recaiu sobre textos produzidos em diferentes níveis de escolarização. Em todas as situações pesquisadas, visava-se a esclarecer o processo geral através do qual se vai continuamente constituindo e modificando a complexa relação entre o sujeito e a linguagem, especialmente no interior da escola. As autoras argumentam que, pelo fato de darem maior visibilidade a alguns aspectos desse processo, os dados idiossincráticos e singulares podem contribuir para uma discussão mais profunda da natureza da relação entre sujeito e linguagem no âmbito da própria teoria da linguagem:

Quando chamamos a atenção para o interesse teórico dos episódios e seus dados muitas vezes singulares, fazemos isso não do interior de uma teoria psicológica especifica, com seu conjunto de pressupostos teóricos, hipóteses, axiomas e métodos que obrigam a certos procedimentos de pesquisa, mas no contexto de um conjunto de estudos da linguagem em que à interlocução, aos atores sociais, à micro e macrohistória é atribuído um estatuto teórico específico, em virtude das perguntas que se deseja ver incorporadas por uma teoria da linguagem mais abrangente, interessada não apenas nas características formais do objeto lingǘstico, mas, também, no modo e na história da sua constituição [...] (ABAURRE; FIAD; MAYRINK-SABINSON, 1997a, p. 21).

Nos estudos específicos sobre a aquisição da escrita por crianças, Abaurre, Fiad e Mayrink-Sabinson (1997b) assumem que os erros cometidos pelos aprendizes são, na verdade, preciosos indícios de um processo em curso de aprendizagem da representação escrita da linguagem. Elas criticam as práticas e os estudos pedagógicos que ignoravam esse fato, referindose a um periodo de "surdas batalhas" entre, de um lado, professores que, muitas vezes sem sucesso, corrigiam esses erros, e, de outro lado, alunos que tentavam ver sentido em orientações didáticas em conflito com suas hipóteses. No que diz respeito especificamente aos erros, as autoras dizem 
ter procurado saber que fato singular, que aspecto de contexto, forma ou significação lingüística pode ter adquirido relevância para o sujeito, colocando-se como objeto de preocupação para ele na busca de soluções para seus problemas epistemológicos, ainda que essas soluções muitas vezes possam ser caracterizadas como episódicas e circunstanciais.

No trabalho "(Re)escrita e estilo", pertencente à coletânea em discussão, Fiad (1997) diz que, dentro do paradigma indiciário, dados singulares e particulares que, em outra perspectiva teórica, seriam considerados marginais podem vir a se tornar reveladores e significativos. Assim, o paradigma indiciário recupera a possibilidade de examinar pormenores e marcas individuais presentes nas várias atividades humanas, entre elas, a linguagem; permite lidar com diferenças, mais do que com semelhanças, com anormalidades, mais do que com normalidades; por fim, permite ao analista ir em busca de explicações, mais do que tentar encontrar evidências para explicações e teorias já existentes.

Como já haviamos mostrado, Ginzburg (1999) reivindica, para o paradigma indiciário, outros critérios de rigor e cientificidade, compativeis com situações de pesquisa em que a singularidade dos dados é decisiva. Pensamos que esse raciocínio é válido no caso dos estudos em linguagem, porque cada ocorrência do discurso é única em si mesma. A crítica de Ginzburg à redução feita pela Filologia e pela crítica literária nos textos analisados aplica-se perfeitamente à análise de situações discursivas escolares. Nesse caso, uma pesquisa meramente quantitativa ou que se detenha na superfície do discurso propriamente dito pode escamotear dados muito interessantes, na medida em que manifestações singulares materializam algo das complexas relações entre os alunos, a língua e a escola.

Com base nas sugestões de Minayo (2000), Certeau (1999) e Cruz Neto (1994), é legítimo perseguirmos o propósito de integrar conhecimentos, ultrapassando as fronteiras entre campos científicos já constituídos, para tentar explicar aspectos diversificados da produção do discurso escolar, ou, pelo menos, reformular caminhos de pesquisa e indicar novos objetos de investigação para as Ciências da Linguagem. Sem avançar na direção dessa abertura epistemológica, não teríamos como dar conta das muitas "bricolagens" que fazem os alunos no cotidiano da escola.

Em Abaurre (1995), afirma-se que somente um programa de pesquisa que antecipadamente já definiu hipóteses e resultados pode se dispensar 
da pergunta: "O que nos ensinam os dados ou acontecimentos?". Aos que dispensam a pergunta, resta buscar exemplos e amostras que corroborem definições e pontos de vista prévios. A outra possibilidade seria partir do microcosmo do texto ou da resposta encontrada para formular hipóteses mais amplas sobre o funcionamento da linguagem. Isso exige do pesquisador a escolha de técnicas de coleta compatíveis com o objeto investigado. Daí a relevância de acionar mecanismos diversos de interpretação. É o que se impõe quando fazemos pesquisa qualitativa em linguagem utilizando o paradigma indiciário e seus procedimentos abdutivos de pesquisa. Acreditamos, juntamente com Abaurre (1997), que a articulação entre as teorias da enunciação e esses procedimentos são os mais adequados para tematizar a linguagem como processo discursivo e, particularmente, as manifestações discursivas que se dão na instituição escolar.

\section{Notas}

1. Cf. Burke (1992), para quem a história tradicional corresponde a uma "visão de cima"; trata-se de relatos dos grandes feitos dos grandes homens, elaborados a partir de documentos oficiais, negligenciando-se outras fontes e evidências dos fatos históricos.

2. Cf. também Corazza (1996, p. 120): "Os instrumentos para a constituição de um problema de pesquisa [...] não podem ser outros que os das teorizações que já foram produzidas. Por isso, a nosso modo e com nossos limites, temos o dever de nos apropriar [...] dos territórios teóricos e com eles estabelecer interlocuções, ao mesmo tempo em que vamos reelaborando as teorias."

3. A expressão designa o relatório elaborado pelo Dr. Henrique Walter Pinotti, chefe da equipe médica que assistiu o presidente Tancredo Neves, e publicado no jornal O Estado de São Paulo de 18/04/85. O referido texto foi analisado a partir da quantificação das construções passivas, buscando-se verificar a tipologia dessa construção, sua freqüência e distribuição no texto (INDURSKY, 1990).

4. Demo (1995) diz que o dado não é evidente, mas feito evidente no quadro de referência em que é colhido e discutido.

5. Marcuschi (2001) também aponta o valor do dado imprevisível produzido na interação verbal; acha que, do ponto de vista epistemológico, 
essa produtividade metodológica do dado irregular é um dos fatores que motivam a perspectiva interpretativa dominante nos estudos atuais sobre a interação verbal.

6. Peirce, citado por Abaurre (1997), define a abdução como uma modalidade de inferência que consiste na busca de conclusões pela interpretação racional de sinais, indices ou signos.

\section{Referências}

ABAURRE, M. B. M. Uma história individual. In: ABAURRE, M. B. M.; FIAD, R. S.; MAYRINK-SABINSON, M. L. T. Cenas de aquisição da escrita: o sujeito e o trabalho com o texto. Campinas: Associação de Leitura do Brasil/Mercado de Letras, 1997. p. 79-115.

; FIAD, R. S.; MAYRINK-SABINSON, M. L. T. Cenas de aquisizão da escrita: o sujeito e o trabalho com o texto. Campinas: Associação de Leitura do Brasil/Mercado de Letras, 1997a.

FIAD F Em busca de pistas. In: ABAURRE, M. B. M. ta. o sujeito e o trabalho com o texto. Campinas: Associação de Leitura do Brasil/Mercado de Letras, 1997b. p.13-36.

ABAURRE, M. B. M. et al. Considerações sobre a utilização de um paradigma indiciário na análise de episódios de refacção textual. Trabalbos em Lingüistica Aplicada, Campinas, n. 25, p. 5-23, jan./jun.1995.

ALVES, R. Filosofia da Ciência: introdução ao jogo e suas regras. São Paulo: Loyola, 2000.

ANDRÉ, M. E. D. A. A pesquisa no cotidiano escolar. In: FAZENDA, I. (Org.). Metodologia da pesquisa educacional. 6. ed. São Paulo: Cortez, 2000. p. $35-45$.

. Texto, contexto e significados: algumas questões na análise de dados qualitativos. Cadernos de Pesquisa, São Paulo, n. 45, p. 66-71, maio 1983.

BURKE, P. Abertura: a Nova História, seu passado e seu futuro. In: BURKE, P. (Org.). A escrita da História: novas perspectivas. São Paulo: Editora da UNESP, 1992. p.7-37. 
CALVINO, I. Seis propostas para o próximo milênio: lições americanas. São Paulo: Companhia das Letras, 1990.

CAVALCANTI, M. C.; MOITA LOPES, L. P. Implementação de pesquisa na sala de aula de línguas no contexto brasileiro. Trabalhos em Lingüística Aplicada, Campinas, n.17, p. 133-144, jan./jun.1991.

CERTEAU, M. A cultura no plural. Campinas: Papirus, 1995.

- A invenção do cotidiano. 4. ed. Petrópolis: Vozes, 1999. (Artes de fazer; 1). CORACINI, M. J. Análise de discurso: em busca de uma metodologia. D.E.L.T.A.- Documentafão e Estudos em Lingüistica Teórica e Aplicada, São Paulo, v. 7, n.1, p. 333-355, 1991.

CORAZZA, S. M. Labirintos da pesquisa, diante dos ferrolhos. In: COSTA, M. V. (Org.). Caminhos investigativos: novos olhares na pesquisa em educação. Porto Alegre: Mediação, 1996, p. 105-131.

COSTA, M. V. Novos olhares na pesquisa em Educação. In: COSTA, M. V. (Org.). Caminhos investigativos: novos olhares na pesquisa em Educação. Porto Alegre: Mediação, 1996. p. 9-17.

CRUZ NETO, O. O trabalho de campo como descoberta e criação. In: MINAYO, M. C. S. (Org.). Pesquisa social: teoria, método e criatividade. 18. ed. Petrópolis: Vozes, 1994. p. 51-66.

DEMO, P. Metodologia científica em Ciências Sociais. 3. ed. São Paulo: Atlas, 1995.

DESLANDES, S. F. A construção do projeto de pesquisa. In: MINAYO, M. C. S. (Org.). Pesquisa sociat: teoria, método e criatividade. 18. ed. Petrópolis: Vozes, 1994. p. 31-50.

DUARTE, C. Uma análise de procedimentos de leitura baseada no paradigma indiciário. 1998. Dissertação (Mestrado em Lingüística) - Instituto de Estudos da Linguagem da Universidade Estadual de Campinas. Campinas.

FIAD, R. S. (Re)escrita e estilo. In: ABAURRE, M. B. M.; FIAD, R. S.; MAYRINK-SABINSON, M. L. T. Cenas de aquisiżão da escrita: o sujeito e o trabalho com o texto. Campinas: Associação de Leitura do Brasil/Mercado de Letras, 1997. p.155-173.

FOUCAULT, M. A ordem do discurso. 4. ed. São Paulo: Loyola, 1998. 
GINZBURG, C. Mitos, emblemas e sinais. morfologia e História. 3.ed. São Paulo: Companhia das Letras, 1999.

O queijo e os vermes: o cotidiano e as idéias de um moleiro perseguido pela Inquisição. 10. ed. São Paulo: Companhia das Letras, 1998.

GOMES, R. A análise de dados em pesquisa qualitativa. In: MINAYO, M. C. S. (Org.). Pesquisa social: teoria, método e criatividade. 18. ed. Petrópolis: Vozes, 1994. p. 67-80.

GONSALVES, E. P. Escolhendo o percurso metodológico. In: GONSALVES, E. P. Conversas sobre iniciação à pesquisa cientifica. Campinas: Alínea, 2001. p. 61-73.

INDURSKY, F. A. quantificação na análise do discurso: quantidade equivale a qualidade? D.E.L.T.A. - Documentação e Estudos em Lingüistica Teórica e Aplicada, São Paulo, v. 6, n.1, 1990. p. 19-40.

LAVILLE, C.; DIONNE, J. A construção do saber: manual de metodologia de pesquisa em Ciências Humanas. Belo Horizonte: Editora da UFMG; Porto Alegre: Artmed, 1999.

LEVI, G. Sobre a micro-História.In: BURKE, P. (Org.). A escrita da História: novas perspectivas. São Paulo: Editora da UNESP, 1992. p. 133-161.

LÜDKE, M.; ANDRÉ, M. E. D. A. Pesquisa em Educação: abordagens qualitativas. São Paulo: EPU, 1986.

LUNA, S. V. O falso conflito entre tendências metodológicas. In: FAZENDA, I. (Org.). Metodologia da pesquisa educacional. 6.ed. São Paulo: Cortez, 2000. p. 21-33.

MAINGUENEAU, D. Novas tendências em análise do discurso. 3. ed. Campinas: Pontes/Ed. da UNICAMP, 1997.

MAINGUENEAU, D. Pragmática para o discurso literário. São Paulo: Martins Fontes, 1996.

MARCUSCHI, L. A. Aspectos da questão metodológica na análise da interação verbal: o continuum qualitativo-quantitativo. Revista Latino-Americana de Estudos do Discurso, Venezuela, v. 1, n.1, ago. 2001. p. 23-42.

MARQUES, W. O quantitativo e o qualitativo na pesquisa educacional. Avaliação, Campinas, ano 2, n.3 (5), p. 19-32, set. 1997. 
MASON, J. Introduction: asking difficult questions about qualitative research. In: Qualitative researcbing, London: Sage Publications, 1997. p. 1-7.

MATALLO JR., H. A explicação científica. In: CARVALHO, M. C. M. (Org.). Construindo o saber. metodologia científica: fundamentos e técnicas. 2. ed. Campinas: Papirus, 1989a. p. 39-62.

Mito, metafísica, ciência e verdade. In: CARVALHO, M. C. M. (Org.). Construindo o saber. metodologia científica: fundamentos e técnicas. 2. ed. Campinas: Papirus, 1989b. p. 29-38.

MINAYO, M. C. S. Ciência, técnica e arte: o desafio da pesquisa social. In: - (Org.). Pesquisa social: teoria, método e criatividade. 18. ed.

Petrópolis: Vozes, 1994. p. 9-29.

. O desafio do conbecimento: pesquisa qualitativa em saúde. 7. ed. São

Paulo: Hucitec; Rio de Janeiro: Abrasco, 2000.

MONTEIRO, R. C. A pesquisa qualitativa como opção metodológica. Pro-posiçoes, Campinas, n. 5, p. 27-34, ago.1991.

MORIN, E. A noção de sujeito. In: SCHNITMAN, D. F. (Org.). Novos paradigmas, cultura e subjetividade. Porto Alegre: Artmed, 1996a. p. 45-55.

Complexidade e liberdade. In: BESNIER, J. M. A sociedade em busca de valores: para fugir à alternativa entre o cepticismo e o dogmatismo. Lisboa: Instituto Piaget, 1996b. p. 239-257.

Epistemologia da complexidade. In: SCHNITMAN, D. F. (Org.). Novos paradigmas, cultura e subjetividade. Porto Alegre: Artmed, 1996c. p. 274-289.

ORLANDI, E. P. Análise de discurso: princípios e procedimentos. Campinas: Pontes, 1999.

A leitura proposta e os leitores possíveis. In: (Org.). $A$ leitura e os leitores. Campinas: Pontes, 1998a.p. 7-24.

- As formas do silêncio: no movimento dos sentidos. 4. ed. Campinas: Editora da UNICAMP, 1997.

. Discurso e leitura. São Paulo: Cortez; Campinas: Editora da UNICAMP, 1988. 
ORLANDI, E. P. O lugar das sistematicidades lingüísticas na análise do discurso. In: D.E.L.T.A. - Documentą̧ão e Estudos em Lingüística Teórica e Aplicada, São Paulo, v. 10, n. 2, p. 295-307,1994.

O próprio da análise do discurso. Campinas: UNICAMP/Laboratório de Estudos Urbanos, 1998b. p. 17-22. (Escritos; 3).

PÊCHEUX, M. Análise automática do discurso. Em: GADET, F; HAK, T. (Org.). Por uma análise automática do discurso: uma introdução à obra de Michel Pêcheux. 3. ed. Campinas: Editora da UNICAMP, 1997a. p. 61161.

$1997 \mathrm{~b}$.

O discurso: estrutura ou acontecimento. 2.ed. Campinas: Pontes,

PÉREZ GÓMEZ, A. I. Compreender o ensino na escola: modelos metodológicos de investigação educativa. In: GIMENO SACRISTÁN, J;; PÉREZ GÓMEZ, A. I. Compreender e transformar o ensino. 4. ed. Porto Alegre: Artmed, 1998. p. 99-117.

PIMENTEL, E. Sujeitos leitores, sujeitos autores: indícios de histórias de leituras na produção de textos escolares. 1998. Dissertação (Mestrado em Lingüística) - Instituto de Estudos da Linguagem da Universidade Estadual de Campinas. Campinas.

QUARTAROLLA, A. A. Relatório de pesquisa/CNPq. 1994. Mimeografado.

SÁNCHEZ GAMBOA, S. A dialética na pesquisa em educação: elementos de contexto. In: FAZENDA, I. (Org.). Metodologia da pesquisa educacional. 6. ed. São Paulo: Cortez, 2000. p. 91-115.

SANTOS, B. S. Introdução a uma ciência pós-moderna. 3. ed. Rio de Janeiro: Graal, 2000a.

Pela mão de Alice: o social e o político na pós-modernidade. 7. ed. São Paulo: Cortez, 2000b.

Um discurso sobre as ciências. 12. ed. Porto: Afrontamento, 2001.

SHARPE, J. A história vista de baixo. In: BURKE, P. (Org.). A escrita da História: novas perspectivas. São Paulo: Editora da UNESP, 1992. p. 3962. 
THIOLLENT, M. J. M. Aspectos qualitativos da metodologia de pesquisa com objetivos de descrição, avaliação e reconstrução. Cadernos de Pesquisa, São Paulo, n. 49, p. 45-50, maio 1984.

TRIVIÑOS, A. N. S. Introdução à pesquisa em Ciências Sociais: a pesquisa qualitativa em Educação. São Paulo: Atlas, 1987.

VEIGA-NETO, A. J. Olhares... In: COSTA, M. V. (Org.). Caminhos investigativos: novos olhares na pesquisa em Educação. Porto Alegre: Mediação, 1996. p. 19-35. 
Qualitative research in Education and Language: history and validation of the indicative paradigm

\section{Abstract:}

This theoretical study is part of doctoral research in Linguistics at the University at Campinas. It is specifically an adaptation of a chapter concerning qualitative research in education that justifies the option for the indicative paradigm for the study of phenomenon in the field of institutional evaluation and learning in language. The paper is divided in six parts: a characterization of the classic scientific paradigm; a brief history of the crisis of the classic paradigm; a conceptual discussion of quantitative research; the existing inter-relations between the quantitative and qualitative aspects of educational research, a commentary on the data and the analytic procedures; a specific approach to the indicative paradigm, with an indication of its pertinence and relevance to educational research as a whole and for the treatment of language phenomenon within the school.

Key words: Educational research. Qualitative research. Education and language-research.
Recherque qualitative en Éducation et Langage: histoire et validation du paradigme indiciaire

\section{Résumé:}

Cette étude, de type théorique, est issue de notre thèse de doctorat en linguistique soutenue à l'Université de Campinas. Dans un chapitre dedié à la discussion de la recherche qualitative en éducation, nous avons justifié le choix du paradigme indiciaire pour l'étude de phénomènes dans le champs de l'évaluation institutionnelle et de l'apprentissage en langage. L'étude est divisée en six parties, dans lesquelles sont présentées: (1) une caractérisation du paradigme scientifique classique; (2) un bref historique de la crise du paradigme classique; (3) une discussion conceptuelle sur la recherche qualitative; (4) les rapports existants entre des aspects quantitatif et qualitatif de le recherche en éducation; (5) un commentaire sur les données et les procédures analytiques; (6) une approche spécifique du paradigme indiciaire, conténant des indications sur sa pertinence et son importance pour la recherche éducationnelle dans son ensemble et pour le traitement des phénomènes du langage à l'intérieur de l'école.

Mots-Clés: Recherche éducationnelle. Recherche qualitative. Éducation et langage-recherche. 


\section{Livia Suassuna}

Rua Marechal Rondon, 120/902 - Casa Forte - 52.061-050 - Recife, PE Fones: (81) $3267-5874 \mathrm{e}$ (81) $9421-2935$

Fax: (81) 2126-8320

E-mail:1suassuna@nlink.com.br / livia.suassuna@ufpe.br

Recebido em : 13/12/2007

Aprovado em: 15/3/2008 